\title{
17p13.1 Microduplication Syndrome in a Child, Familial Short Stature, and Growth Hormone Deficiency: A Case Report and Review of the Literature
}

\author{
Sofia Leka-Emiri ${ }^{a}$ Vassilios Petrou $^{a}$ Emmanouil Manolakos $^{d}$ \\ Loretta Thomaidis $^{c}$ Aspasia Fotinou $^{b}$ Elpis Vlachopapadopoulou ${ }^{a}$ \\ Stefanos Michalacos ${ }^{a}$ \\ Departments of a Endocrinology, Growth and Development, ${ }^{b}$ Biochemistry and Hormonology, and ${ }^{c}$ Developmental \\ Assessment Unit, Department of Pediatrics, P\&A Kyriakou Children's Hospital, School of Medicine, National and \\ Kapodistrian University of Athens, and ${ }^{\mathrm{d}}$ Access to Genome (ATG P.C.), Clinical Laboratory Genetics, Athens, Greece
}

\section{Established Facts}

- Familial short stature is considered a "normal" variation of growth and is the most common cause of short stature with a prevalence of $40 \%$ among children growing beyond $<-2$ SD for the same sex and age.

- The prevalence of growth hormone deficiency is reported to occur in 1:4,000 to 1:10,000 among children.

\section{Novel Insights}

- Growth hormone deficiency should be investigated in familial short stature.

- Developmental disabilities and short stature should prompt CGH analysis.

- The 17p13.1 microduplication syndrome may be associated with growth hormone deficiency.

\section{Keywords}

Comparative genomic analysis · Familial short stature ·

Growth hormone deficiency · Microduplication syndrome $17 p 13.1$

\section{Abstract}

To date, 6 cases of 17p13.1 microduplications have been described in the literature. Intellectual disability is the core fea- ture, together with minor facial dysmorphisms and obesity. We describe the first case of a young patient with a maternally inherited microduplication in 17p13.1 presenting with growth hormone deficiency. The boy was addressed to the endocrine division for growth retardation (weight and height $<3$ rd percentile). Besides minor facial dysmorphisms, physical and neurological examinations were normal except for motor dyspraxia. Basic blood tests and endocrinological investigations were normal, but IGF1 levels were low for his

\section{KARGER}

(C) 2018 S. Karger AG, Basel

E-Mail karger@karger.com

www.karger.com/msy
Sofia Leka-Emiri, MD, MSc, PhD

Department of Endocrinology, Growth and Development

P\&A Kyriakou Children's Hospital, Levadias Str.

GR-11527 Athens (Greece)

E-Mail sofialekaemiris@gmail.com 
age. Growth hormone deficiency was confirmed. Hypothalamic pituitary MRI was normal. His karyotype was 46XY. Array-CGH analysis detected a $422-k b$ copy number gain in the spanning region 17p13.1 inherited from his mother. Although familial short stature is considered a "normal" variation of growth retardation, hormonal and genetic investigation is essential in the etiological diagnosis.

(C) 2018 S. Karger AG, Basel

The short arm of chromosome 17 is associated with a large variety of copy number losses and gains, resulting from nonallelic homologous recombinations between low copy repeats that lead to several well-characterized genomic disorders. While the $17 \mathrm{p} 13.1$ microdeletion syndrome is well described [Komoike et al., 2010; Carvalho et al., 2014], to date only few cases of 17p13.1 microduplication have been reported [Belligni et al., 2012; Coutton et al., 2012; Kuroda et al., 2014; Mooneyham et al., 2014; Maini et al., 2016], and a distinct phenotype has not yet been defined. Intellectual disability was observed in all patients as the hallmark feature. In addition, a wide range of clinical signs has been reported, such as behavioral abnormalities, growth retardation, dysmorphisms, obesity, and other endocrinological abnormalities such as insulin resistance and diabetes as well as dyslipidemia and hypothyroidism (Understanding Rare Chromosome and Gene Disorders [UNIQUE]): https://www.rarechromo.org). Here, we report a 7-year-old boy with a 17p13.1 microduplication who, along with intellectual disability and mild facial dysmorphism, presented with growth retardation due to growth hormone (GH) deficiency.

\section{Case Report}

The boy was first examined at the age of 3.5 years for growth retardation: his weight was $12.8 \mathrm{~kg}$ ( $3 \mathrm{rd}$ percentile) and his height was $89.1 \mathrm{~cm}$ (<3rd percentile). He is the only child of healthy unrelated parents of Caucasian ancestry. His mother is short (height: $148.5 \mathrm{~cm}$, $<3$ rd percentile) and was diagnosed with learning difficulties at school. His father is also short (height: $154.5 \mathrm{~cm},<3 \mathrm{rd}$ percentile) with normal intelligence, and no other family history of intellectual disability or endocrine disorder was reported. The child was born by normal spontaneous vaginal delivery at 40 weeks' gestation after an uneventful pregnancy (weight: $3,070 \mathrm{~g}$, 25th percentile; length: $47 \mathrm{~cm}$, $3 \mathrm{rd}$ percentile, and head circumference: $34 \mathrm{~cm}, 25$ th percentile). During infancy and early childhood, the boy showed mild developmental delay. At 7 years of age, he was underweight $(18 \mathrm{~kg},-2$ $\mathrm{SD})$, but his height was more severely compromised $(105 \mathrm{~cm},-3.2$ $\mathrm{SD}$ ). Apart from minor facial dysmorphic features such as moderate micrognathia, low-set ears, and a long philtrum, no other abnormalities, asymmetries, or skeletal deformities were found (Fig. 1).

17p13.1 Microduplication Syndrome and Familial Short Stature

\section{Methods and Results}

Neurological examination showed oral motor dyspraxia without focal neurological signs. EEG recordings revealed slow background activity without paroxysmal features. Basic hematologic and biochemistry tests as well as endocrinological investigation revealed normal thyroid and cortisol levels, but IGF1 levels were low for his age. $\mathrm{GH}$ response to 2 different stimulation tests was $<10 \mathrm{ng} / \mathrm{mL}$, consistent with GH deficiency (Table 1). Hypothalamic pituitary MRI was normal.

Taking the familial pattern of short stature and intellectual disability into consideration, genetic investigation was prompted. A chromosome analysis revealed a normal male karyotype. Further investigation with array CGH was performed by hybridizing the sample against a male human reference commercial DNA sample (Promega Biotech) using an array-CGH platform which includes 60,000 oligonucleotides distributed across the entire genome (Agilent Technologies). Only those copy number changes that affect at least 5 consecutive probes with identically oriented change were considered as CNVs. For the majority of the genome, the average genomic power of resolution of this analysis was $200 \mathrm{~kb}$. ArrayCGH analysis detected a $422-\mathrm{kb}$ copy number gain in the spanning region $17 \mathrm{p} 13.1$. The breakpoint was mapped between genomic coordinates chr17:6,902,072-7,324,005 (genomic coordinates are listed according to genomic build GRCh37/hg19) (Fig. 2). No additional aberrations were detected. Both parents were found to have normal karyotypes, but the mother's and son's array-CGH results were identical, indicating that the boy had inherited the duplication from his mother. The father's array-CGH analysis was normal.

\section{Discussion}

In the literature, 6 cases with $17 \mathrm{p} 13.1$ microduplications have been described so far, and duplications ranged between 62.50 and $788 \mathrm{~kb}$ [Belligni et al., 2012; Coutton et al., 2012; Maini et al., 2016; Kuroda et al., 2014; Mooneyham et al., 2014]. Detailed clinical information of all cases regarding the $17 \mathrm{p} 13.1$ duplication syndrome is reported in Table 2. The de novo 586-kb duplication $(6,690,620$ $7,276,764)$ in $17 \mathrm{p} 13.1$ described by Coutton et al. [2012] and the de novo 788 -kb duplication $(6,610,939-7,399,323)$ in 17p13.1 described by Mooneyham et al. [2014] share a large duplicated region with our case presenting with a 422 -kb duplication $(6,902,072-7,324,005)$.

Mol Syndromol 2018;9:300-305

DOI: $10.1159 / 000494681$ 


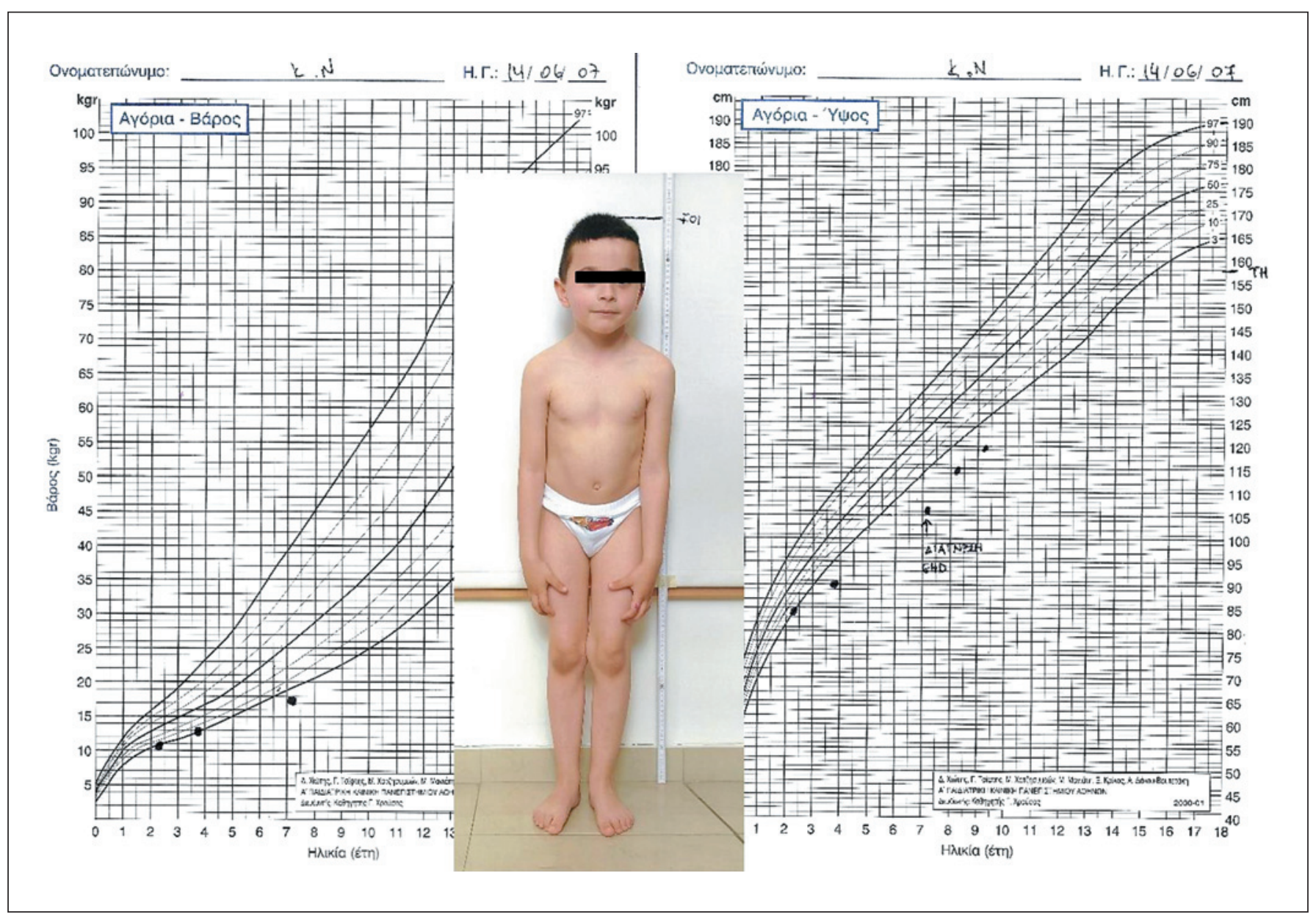

Fig. 1. Growth curves and physical appearance of the patient at the age of 7 years.

Table 1. Hormone levels

\begin{tabular}{ll}
\hline & Levels \\
\hline IGF1 & $57(17-248) \mathrm{ng} / \mathrm{mL}$ \\
Clonidine stimulation test & GH peak max: $7.6 \mathrm{ng} / \mathrm{mL}(>10 \mathrm{ng} / \mathrm{mL})$ \\
Glucagon stimulation test & GH peak max: $6.06 \mathrm{ng} / \mathrm{mL}(>10 \mathrm{ng} / \mathrm{mL})$ \\
TSH & $2.4 \mu \mathrm{IU} / \mathrm{mL}(0.5-6)$ \\
FT4 & $1.19 \mathrm{ng} / \mathrm{dL}(0.9-1.9)$ \\
Cortisol (8 a.m.) & $15.1 \mu \mathrm{g} / \mathrm{dL}(6.2-18)$ \\
\hline
\end{tabular}

FT4, free thyroxine; GH, growth hormone; ICF1, insulin-like growth factor 1 ; TSH, thyroid-stimulating hormone.

To our knowledge, our case is the second described so far, with growth retardation and the first with a detected GH deficiency. The only child described in the literature with growth retardation and $17 \mathrm{p} 13.1$ microduplication was a boy with Russel-Silver syndrome [Coutton et al., 2012].
In that case, although serum GH levels were normal, GH therapy was initiated at 4.5 years of age, due to small for gestational age. At 15 years, he achieved puberty, his height was $158 \mathrm{~cm}$ (5-10th centile), and his weight $48 \mathrm{~kg}$ (10-25th centile). In our case, rhGH was initiated at 7 years with consistent growth acceleration since then (Fig. 1).

Children born with duplication of different regions of chromosome 17 are often, but not always, small and underweight at birth. Feeding difficulties are a major area of concern for families, and infants may have failure to thrive. The hypotonia that is common in babies with a $17 \mathrm{p}$ duplication (regardless of the region duplicated in $17 \mathrm{p})$ can lead to difficulties with sucking and swallowing. Children with a duplication of $17 \mathrm{p}$ often have short stature. Among the 36 genes located in the duplicated region, 2 genes (GABARAP and SLC2A4) have been reported to be related to growth retardation, but their exact role remains uncertain. GABARAP is a $\mathrm{GABA}_{\mathrm{A}}$ receptor-asso-
Leka-Emiri et al. 


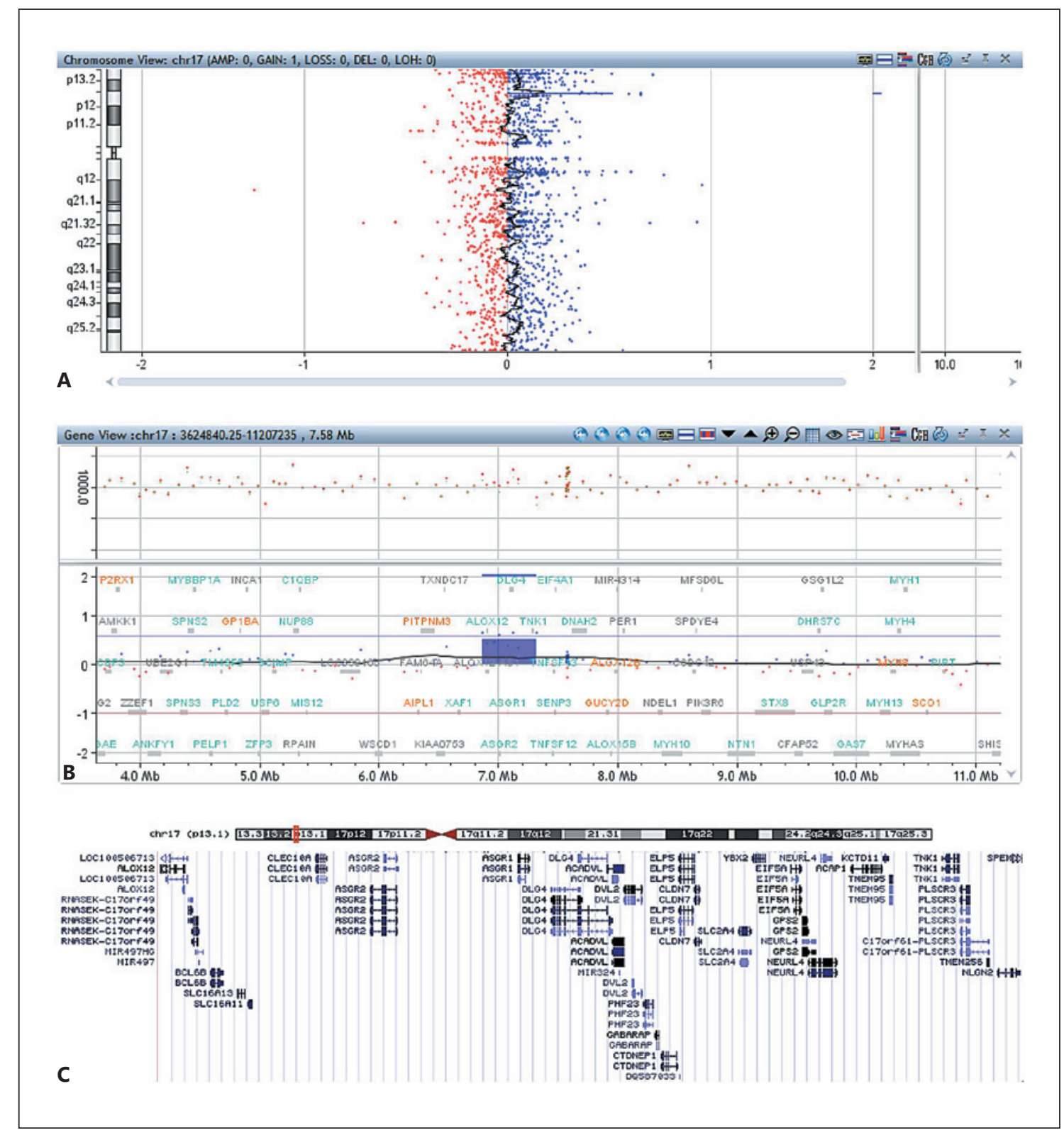

Fig. 2. A Array-CGH analysis detected a 422-kb copy number gain in the spanning region 17p13.1. B The breakpoint was mapped between the genomic coordinates chr17:6,902,072-7,324,005. C Genes and gene predictions located in the duplicated region are taken from http://genome.ucsc.edu. The red box indicates the duplicated region of the 17p13.1 chromosome band.

ciated protein, OMIM 605125 (https://www.ncbi.nlm. nih.gov/omim); knockdown of Gabarap results in dwarfism of the entire zebrafish body. SLC2A4 [solute carrier family 2 (facilitated glucose transporter, member 4), OMIM 138190] encodes for an insulin sensitive glucose transporter, GLUT4. GLUT4 defect has been associated with growth retardation in mice.

17p13.1 Microduplication Syndrome and Familial Short Stature
Many new microdeletion and microduplication syndromes have been identified, and several novel genes associated with short stature as part of contiguous gene syndromes have been discovered [Wit et al., 2016]. BlassnigEzeh et al. [2013] described a 2p16p22 microduplication syndrome with a possible role of duplications of EPAS and RHOQ in chromosome 2p21 in severe short stature and 
Table 2. Clinical information for all cases carrying a 17p13.1 duplication

\begin{tabular}{|c|c|c|c|c|c|c|c|c|}
\hline & $\begin{array}{l}\text { Present case } \\
\text { male, } 7 \text { yrs }\end{array}$ & $\begin{array}{l}\text { Maini } \\
\text { et al. [2016] } \\
\text { male, } 12 \text { yrs }\end{array}$ & $\begin{array}{l}\text { Mooneyham } \\
\text { et al. [2014] } \\
\text { male, } 2 \text { yrs }\end{array}$ & $\begin{array}{l}\text { Mooneyham } \\
\text { et al. [2014] } \\
\text { female, } 29 \text { yrs }\end{array}$ & $\begin{array}{l}\text { Kuroda } \\
\text { et al. [2014] } \\
\text { female, } 9 \text { yrs }\end{array}$ & $\begin{array}{l}\text { Belligni } \\
\text { et al. [2012] } \\
\text { male, } 15 \text { yrs }\end{array}$ & $\begin{array}{l}\text { Couton } \\
\text { et al. [2012] } \\
\text { male, } 4.5 \text { yrs }\end{array}$ & Total \\
\hline Intellectual disability & + & + & & + & + & + & + & $6 / 7$ \\
\hline Developmental delay & + & & + & & & & & $2 / 7$ \\
\hline Sociable & & + & & & & + & + & $3 / 7$ \\
\hline Hyperactive & & + & & + & & + & + & $4 / 7$ \\
\hline Food hording & & + & & + & & + & + & $4 / 7$ \\
\hline Afebrile seizures & & & & + & & + & & $2 / 7$ \\
\hline Hypotonia & & & + & & + & + & & $3 / 7$ \\
\hline Nystagmus & & & + & & & & & $1 / 7$ \\
\hline Motor dyspraxia & + & + & & & & & & $2 / 7$ \\
\hline Strabismus & + & + & & + & & & & $3 / 7$ \\
\hline Dysmorphic features & & & & & & & & $7 / 7$ \\
\hline Macrocephaly & & &,$+ \mathrm{A}$ &,$+ \mathrm{R}$ & & &,$+ \mathrm{R}$ & $3 / 7$ \\
\hline Broad forehead & + & & + & & & & + & $3 / 7$ \\
\hline High anterior line & + & & + & + & & & + & $4 / 7$ \\
\hline Flat occiput & + & + & + & & & & & $3 / 7$ \\
\hline Triangular face & + & & + & & & & + & 37 \\
\hline Round face & + & + & & & + & + & & $4 / 7$ \\
\hline Synophrys & & + & & & & & & $1 / 7$ \\
\hline Upslanting palpebral fissures & + & + & & + & + & & & $3 / 7$ \\
\hline Broad nasal tip & + & & + & + & + & + & & $5 / 7$ \\
\hline Upturned nostrils & + & + & & & + & & & $3 / 7$ \\
\hline Micrognathia & + & + & + & + & & + & + & $6 / 7$ \\
\hline Full lips & & & + & + & + & & & $3 / 7$ \\
\hline Clinodactyly & + & & & + & & & + & $3 / 7$ \\
\hline Short hyperconvex nails & & + & & & & & & $1 / 7$ \\
\hline Obesity & & + & & + & + & + & & $4 / 7$ \\
\hline \multicolumn{9}{|l|}{ Endocrinological abnormalities } \\
\hline Hypothyroidism & & & & & & + & & $1 / 7$ \\
\hline Dyslipidemia & & + & & + & + & + & & $4 / 7$ \\
\hline Insulin resistance & & + & & + & + & + & & $4 / 7$ \\
\hline Diabetes & & + & & + & & + & & $3 / 7$ \\
\hline \multirow[t]{3}{*}{ Growth retardation } & + & & & & & & + & $2 / 7$ \\
\hline & $\mathrm{Ht}:-3.2 \mathrm{SD}$ & $\mathrm{Ht}:+0.5 \mathrm{SD}$ & Ht: $-0.8 \mathrm{SD}$ & $\mathrm{Ht}:+0.6 \mathrm{SD}$ & $\mathrm{Ht}:-0.2 \mathrm{SD}$ & $\mathrm{Ht}:-0.8 \mathrm{SD}$ & Ht: -3 SD & \\
\hline & $\mathrm{Wt}:-2 \mathrm{SD}$ & $\mathrm{Wt}:+1.3 \mathrm{SD}$ & $\mathrm{Wt}:-0.2 \mathrm{SD}$ & $\mathrm{Wt}:+1.8 \mathrm{SD}$ & $\mathrm{Wt}:+2.1 \mathrm{SD}$ & $\mathrm{Wt}:+1.8 \mathrm{SD}$ & & \\
\hline Brain MRI & & & & n.d. & n.d. & & n.d. & \\
\hline Enlarged extra-axial spaces & & & + & & & & & $1 / 7$ \\
\hline Hippocampal anomalies & & + & & & & & & $1 / 7$ \\
\hline Reduced cortical gyration & & + & & & & & & $1 / 7$ \\
\hline Choroid plexus cysts & & & & & & + & & $1 / 7$ \\
\hline
\end{tabular}

A, absolute; Ht, height; n.d., not done; R, relative; Wt, weight; yrs, years; +, present.

delayed bone age [Blassnig-Ezeh et al., 2013]. In short children, microdeletions (in contrast to microduplications) are encountered more frequently than in controls [Dauber et al., 2011]. The 17q21q25 duplication syndrome (17q2125dup) includes developmental delay, distal arthrogryposis, GH insensitivity, disturbed STAT5B, PI3K, and NF-kappaB signaling with a possible role of PRKCA mRNA overexpression [Lukusa and Fryns, 2010; Mul et al., 2012]. Distal 14q duplication syndrome (14q32.2qter) presents with short stature, mild developmental delay, a high forehead, hypertelorism, dysplastic ear helices, short philtrum and cupid bow upper lip, a broad mouth, and micrognathia [Thiel et al., 2008]. Short stature with microcephaly and speech delay is also described in the $5 \mathrm{q} 35.2 \mathrm{q} 35.3$ duplication syndrome (5q35.2q35.3dup) [Franco et al., 2010]. However, for these individual cases, it often remains uncertain if their growth failure is due to the encountered CNV, and which of the genes is responsible for growth delay. Comparison of index cases with previously reported patients and databases such as DECIPHER (http://decipher.sanger.uk) and ECARUCA (http:// www.ecaruca.net) may give hints for candidate genes. 
In addition, 4 genes that are located in the duplicated region (SLC16A11, SLC16A13, CLEC10A, and PLSCR3) have been associated to insulin resistance and glucose intolerance. Our patient has not developed glucose metabolism disorders so far. Minor abnormalities of the genitals are reported in male infants with 17p.13.1 microduplication syndrome, such as hypospadias and cryptorchidism. Micropenis has been seen in a boy with 17 p13 microduplication syndrome [Roos et al., 2009]. Our patient showed no genital abnormalities.

In conclusion, we describe a patient with familial short stature, GH deficiency, and mild developmental delay in association with $17 \mathrm{p} 13.1$ microduplication. For children with familial short stature, endocrinological testing belongs to standard procedures. The patient reported here illustrates the necessity to additionally prompt genetic investigation in these cases. It is noteworthy that $\mathrm{GH}$ deficiency is reported to account for up to $1-2 \%$ in children with short stature; in $30 \%$ of the cases it is a familial trait. Familial short stature is considered a "normal" variation of growth and is the most common cause of short stature with a prevalence of $40 \%$ among children growing beyond $<-2$ SD for the same sex and age [Murray et al., 2016; Wit et al., 2016]. The improvement of molecular techniques in association with careful medical history and physical examination can elucidate the etiology for patients with short stature that previously could be characterized as normal variants. Familial heritability of short stature is of great significance, not only for precise diagnosis, but even more importantly for the future life-long health surveillance and guidance.

\section{Statement of Ethics}

The authors have no ethical conflicts to disclose.

\section{Disclosure Statement}

The authors declare that there is no financial interest or any conflicts of interest.

\section{References}

Belligni EF, Di Gregorio E, Biamino E, Calcia A, Franco LM, de Ravel T, Graham BH, Frenkel SM, Molinatto C, et al: $790 \mathrm{~Kb}$ microduplication in chromosome band 17 p13.1 associated with intellectual disability, afebrile seizures, dysmorphic features, diabetes, and hypothyroidism. Eur J Med Genet 55:222-224 (2012).

$\checkmark$ Blassnig-Ezeh A, Bandelier C, Frühmesser A, Revencu N, Krabichler B, et al: Severe growth retardation, delayed bone age, and facial dysmorphism in two patients with microduplications in $2 \mathrm{p} 16 \rightarrow \mathrm{p} 22$. Am J Med Genet 161: 3176-3181 (2013).

Carvalho CM, Vasanth S, Shinawi M, Russell C, Ramocki MB, et al: Dosage changes of a segment at 17p13.1 lead to intellectual disability and microcephaly as a result of complex genetic interaction of multiple genes. Am J Hum Genet 95:565-578 (2014)

-Coutton C, Devillard F, Vieville G, Amblard F, Lopez G, et al: 17p13.1 microduplication in a boy with Silver-Russell syndrome features and intellectual disability. Am J Med Genet A 158A:2564-2570 (2012).

Dauber A, Yu Y, Turchin MC, Chiang CW, Meng YA, et al: Genome-wide association of copynumber variation reveals an association between short stature and the presence of lowfrequency genomic deletions. Am J Hum Genet 89:751-759 (2011). Van Driessche J, et al: A syndrome of short stature, microcephaly and speech delay is associated with duplications reciprocal to the common Sotos syndrome deletion. Eur J Hum Genet 18:258-261 (2010).

Komoike Y, Shimojima K, Liang JS, Fujii H, Maegaki Y, et al: A functional analysis of GABARAP on 17 p13.1 by knockdown zebrafish. J Hum Genet 55:155-162 (2010).

Kuroda Y, Ohashi I, Tominaga M, Saito T, Nagai J, et al: De novo duplication of 17p13.1-p13.2 in a patient with intellectual disability and obesity. Am J Med Genet A 164:1550-1554 (2014).

Lukusa T, Fryns JP: Pure de novo 17q25.3 micro duplication characterized by micro array $\mathrm{CGH}$ in a dysmorphic infant with growth retardation, developmental delay and distal arthrogryposis. Genet Couns 21:25-34 (2010).

Maini I, Ivanovski I, Iodice A, Rosato S, Pollazzon $\mathrm{M}$, et al: Endocrinological abnormalities are a main feature of $17 \mathrm{p} 13.1$ microduplication syndrome: a new case and literature review. Mol Syndromol 7:337-343 (2016).

Mooneyham KA, Holden KR, Cathey S, Dwivedi A, Dupont BR, Lyons MJ: Neurodevelopmental delays and macrocephaly in $17 \mathrm{p} 13.1 \mathrm{mi}-$ croduplication syndrome. Am J Med Genet A 164:2887-2891 (2014).
Mul D, Wu S, de Paus RA, Oostdijk W, Lankester $\mathrm{AC}$, et al: A mosaic de novo duplication of $17 q 21-25$ is associated with GH insensitivity, disturbed in vitro CD28-mediated signaling, and decreased STAT5B, PI3K, and NFkB activation. Eur J Endocrinol 166:743-752 (2012).

Murray PG, Dattani MT, Clayton PE: Controversies in the diagnosis and management of growth hormone deficiency in childhood and adolescence. Arch Dis Child 101:96-100 (2016).

Roos L, Jønch AE, Kjaergaard S, Taudorf K, Simonsen $\mathrm{H}$, et al: A new microduplication syndrome encompassing the region of the MillerDieker (17p13 deletion) syndrome. J Med Genet 46:703-710 (2009).

Thiel CT, Dörr HG, Trautmann U, Hoyer J, Hofmann K, et al: A de novo $7.6 \mathrm{Mb}$ tandem duplication of $14 \mathrm{q} 32.2$-qter associated with primordial short stature with neurosecretory growth hormone dysfunction, distinct facial anomalies and mild developmental delay. Eur J Med Genet 51:362-367 (2008).

Wit JM, Oostdijk W, Losekoot M, van Duyvenvoorde HA, Ruivenkamp CA, Kant SG: Mechanisms in endocrinology: novel genetic causes of short stature. Eur J Endocrinol 174:R145-173 (2016). 17p13.1 Microduplication Syndrome and Familial Short Stature
Mol Syndromol 2018;9:300-305 DOI: $10.1159 / 000494681$ 